\title{
FEM Model of Structure for Weightlifting in CrossFit in Terms of Material Parameters
}

Josef Soukup ${ }^{1}$, Jan Krmela ${ }^{2,3}$, Vladimíra Krmelová ${ }^{2}$, Blanka Skočilasová1, Artem Artyukhov ${ }^{4}$

${ }^{1}$ Faculty of Production Technology and Management, J. E. Purkyne University in Usti nad Labem. Pasteurova 3334/7, 40001 Usti nad Labem. Czech Republic. E-mails: josef.soukup@ujep.cz, blanka.skocilasova@ujep.cz

${ }^{2}$ Faculty of Industrial Technologies, Alexander Dubcek University of Trencin. I. Krasku 491/30, 02001 Puchov. Slovak Republic. E-mails: jan.krmela@fpt.tnuni.sk, vladimira.krmelova@fpt.tnuni

${ }^{3}$ Faculty of Transport Engineering, University of Pardubice. Studentska 95, 53210 Pardubice. Czech Republic. E-mail: jan.krmela@upce.cz

${ }^{4}$ Processes and Equipment of Chemical and Petroleum-Refineries Department, Sumy State University. Ryms'koho-Korsakova St. 2, 40007 Sumy. Ukraine. E-mail: a.artyukhov@pohnp.sumdu.edu.ua

The paper deals with problem of construction for Weightlifting in CrossFit from point of view of material parameters. The specific structure has to withstand repeated impact loads. Therefore it is also necessary to deal with stress-strain states. Because of behavior of impact loading and elastomers used in FEM computational model, explicit integration scheme and material constitutive models have to be included. To use constitutive models, material parameters have to be well known. In this paper, the 2-parameter Mooney-Rivlin model is used. That is the reason, why this article is focused on obtaining material parameters of elastomers for FEM computational modeling based on their hardness. Mooney-Rivlin parameters can be determined on the basis of the Shore A hardness. There are exist equations which can be used conversion of the mentioned hardness to material parameters of elastomers. The procedure is such that the Shore A hardness is converted to the elastic or shear modulus and then Mooney-Rivlin material parameters are determined from the modulus. But these equations can lead to different results for the same hardness. In this paper, these results are comparison. For create a 3D model the SolidWorks software is used and for FEM analyses well-known the ANSYS Workbench software is used.

Keywords: CrossFit, ANSYS, Elastomer, Shore A hardness, Mooney-Rivlin parameters

\section{Introduction}

The construction for weightlifting in CrossFit exercises has to be able to withstand the repeated impact loads of barbell with the weight up to $160 \mathrm{~kg}$ while the given barbell can fall down from the height of $1300 \mathrm{~mm}$ (Fig. 1) in dependence on built physique body construction of trainee (weightlifter).

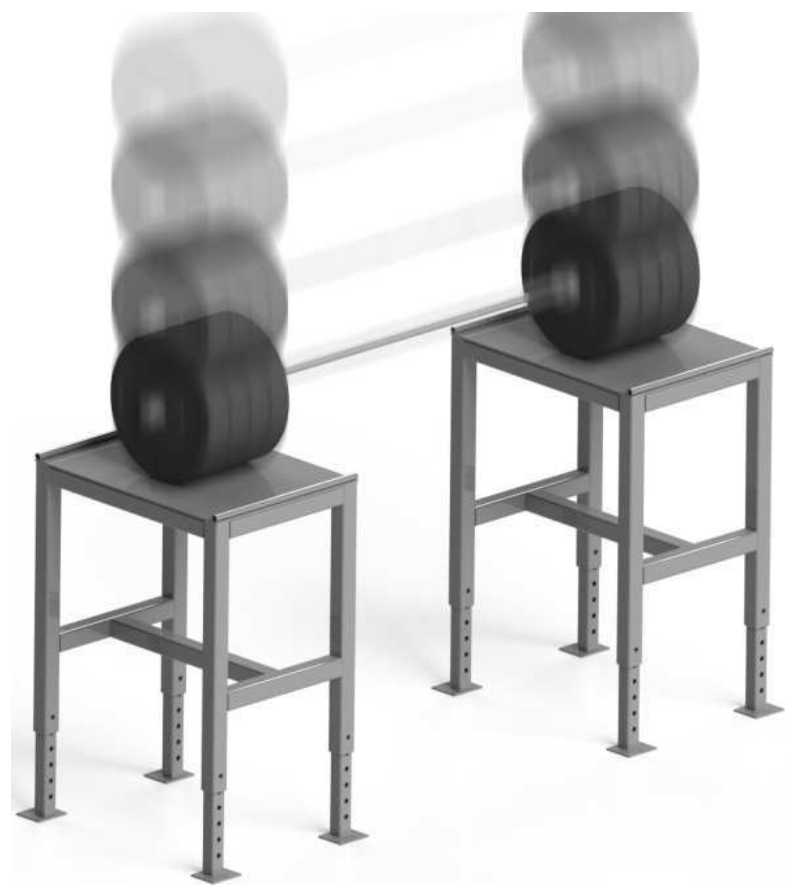

Fig. 1 Image of impact loading as a result of dropped barbell [1]
Based on the prescribed phases of lift and techniques, the principle of the training procedure is that the trainee has to lift the barbell with the maximum possible weigh from the ground to overhead. In the case of the weightlifting, which is one of the training procedures in CrossFit, there are two specific techniques, such as "technical snatch" and "technical clear and jerk". The given techniques are mutually different from the aspect of individual phases or movements of lift to overhead. In community of sportsmen, it is the well known fact that the weight which can be lifted to overhead is generally higher than the weight which is lifted from ground to be in front of the neck and on the shoulders. Based on the mentioned fact, the metal jerk blocks are commonly used as useful workout aid equipment [1]. After the performance of the training or workout activity, the used barbell is dropped onto the given metal jerk blocks. To avoid any injury of trainee as well as to simplify the repeated performance of the training activity, the construction of metal jerk block should be designed with regard to the requirements and needs of trainee.

The design for geometry of construction (metal jerk block) was based on the utilisation of the $3 \mathrm{D}$ modeling in SolidWorks software. The construction of metal jerk block consists of frame with the bracing, matting part with bent lip to keep the plates from rolling off after a drop of barbell plates and finally, there are the legs with adjustable height and they are joined with the frame by help of locking pin. The metal jerk block construction is designed in such a way to be adjustable to the needed height in order to be comfortably used by any trainee or weightlifter with the different height (see Fig. 2). Moreover, using the hollow construction profiles, the design 
of the metal jerk block construction with designation of used materials can be seen in Fig. 3.

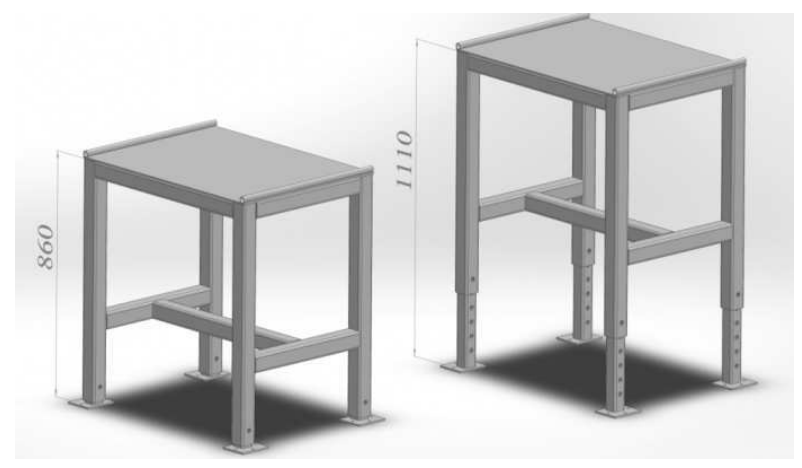

Fig. 2 Design of metal jerk block - minimum height (on the left) and maximum height (on the right) [1]

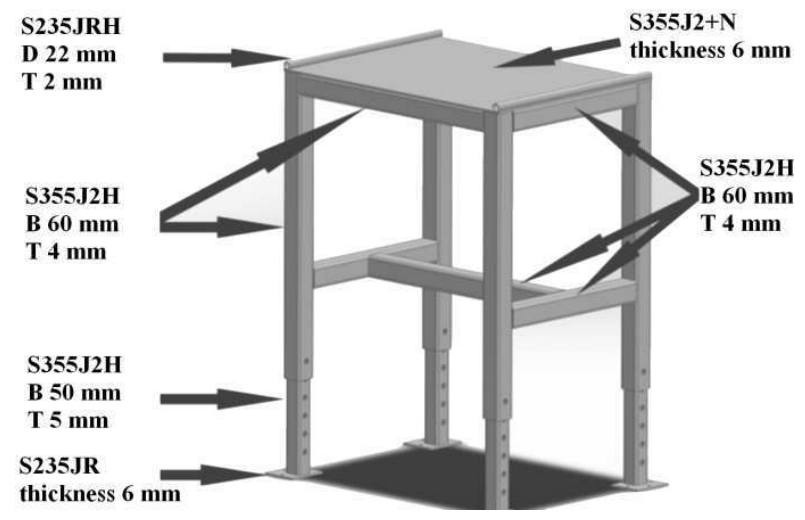

Fig. 3 Final design of metal jerk block [1]

\section{Proposal of computational model from the aspect of material parameters}

Computational model for stress-strain analyses is created in student's version of ANSYS Workbench software because this model was created as a part of the Diploma thesis [1]. The solution of the given problem was based on the proposed algorithm, which is shown in the Fig. 4. The main objective was to analyse and evaluate the metal jerk block construction from the aspect of the stress-strain states and therefore, it was necessary to use explicit dynamic analysis to solve the impact barbell plates loading on the metal jerk block construction.

Barbell weight plates, which are used for weightlifting in CrossFit, are on the basis of elastomeric materials and it means that the hyperelasticity has to be applied in computational model for the correct or even accurate data collection relating to interaction between dropped barbell or barbell weight plate and the metal jerk block. After the production, the weight of the weight plates can be 5,10 , 15,20 and $25 \mathrm{~kg}$. In CrossFit, so called Bumper plates are used as training weight plates and in comparison with weight plates which are used by Olympic weightlifters, the CrossFit weight plates are based on the higher thickness. Using the combination of the individual training weight plates can lead to the achievement of the maximum $220 \mathrm{~kg}$ weight of barbell. In relation to the performance of CrossFit trainees, the best results in weightlifting are commonly not comparable with the results obtained by Olympic weightlifters. The maximum performance of the best CrossFit trainees is about $160 \mathrm{~kg}$ and based on the specifications of producer, the CrossFit weight plates exhibit Shore A hardness of 88 . During investigation, there was the problem with the preparation of the samples for testing procedures, which had been considered to be used in order to obtain stress-strain curves for weight from experimental data and it led to the utilisation of the constitutive two parameter Mooney-Rivlin model, the parameters of which can be determined on the basis of the hardness, using Shore A durometer.

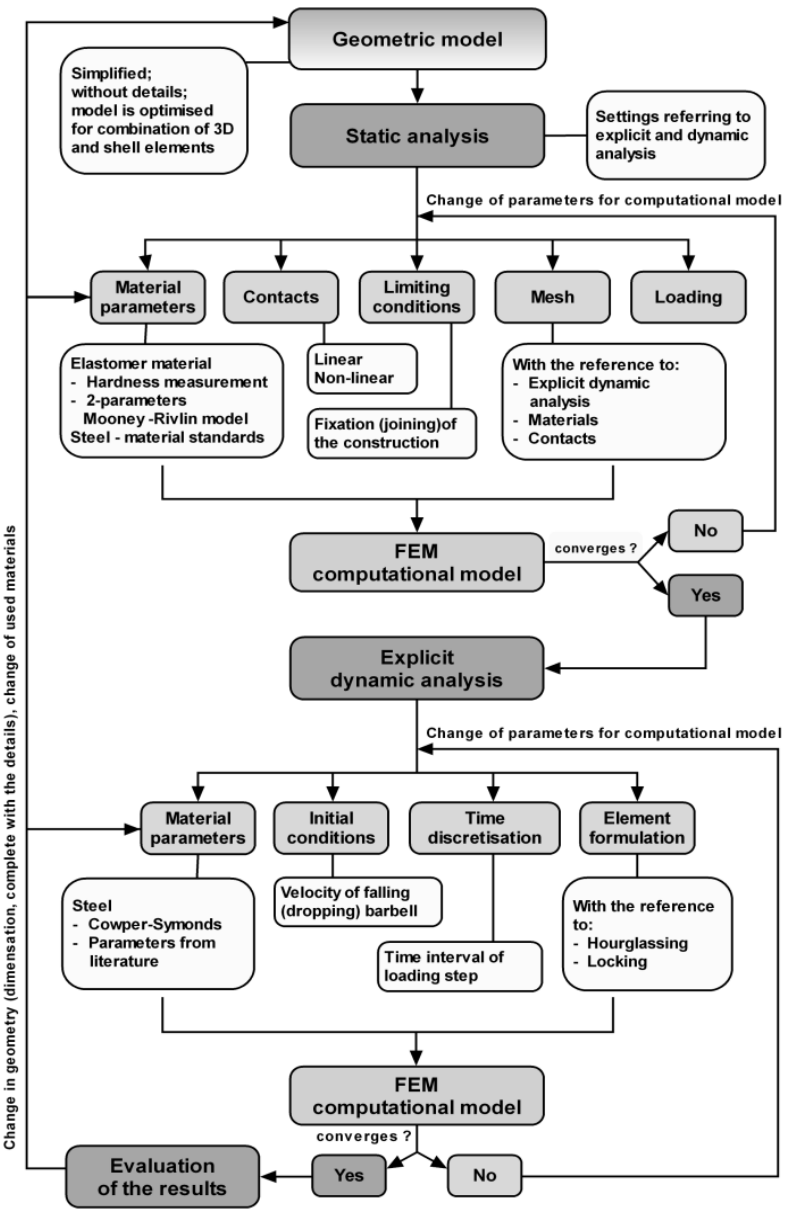

Fig. 4 Algorithm for creation of FEM computational model for construction

\section{Determination of Mooney-Rivlin parameters on the basis of Shore A hardness}

The procedure is such that the Shore A hardness (it is expressed as $A$ in equations) is converted to the elastic modulus $E$ or shear modulus $G$ and then Mooney-Rivlin (MR) parameters are determined from the modulus. Following equations can be used conversion of the mentioned hardness:

- Gent equation [2]:

$$
E=\frac{0.0981 \cdot(56+7.62336 \cdot A)}{0.137505 \cdot(254-2.54 \cdot A)}[M P a]
$$

- equation [3]:

$$
E=\exp (0.0235 \cdot A-0.6403)[M P a],
$$


- equation [4], but the elastic modulus is expressed in [psi]:

$$
E=11.427 \cdot A-0.4445 \cdot A^{2}+0.0071 \cdot A^{3}[M P a] \text {, }
$$

- Batterman/Köhler equation [5] is based on expression dependence between shear modulus and Shore A hardness:

$$
G=0.086 \cdot 1.045^{A}[\mathrm{MPa}] .
$$

These equations can lead to different results of moduli for the same Shore A hardness.

Mooney-Rivlin parameters, such as $C_{10}$ and $C_{01}$ are calculated according to: ted as:

$$
G=2 \cdot\left(C_{10}+C_{01}\right)[M P a], C_{01}=(\text { from } 0.2 \text { to } 0.25) \cdot C_{10} \text {. }
$$

The parameter of incompressibility $d$ can be calcula-

$$
d=\frac{2 \cdot(1-2 \cdot v)}{C_{10} \cdot(5 \cdot v-2)+C_{01} \cdot(11 \cdot v-5)}\left[\mathrm{MPa}^{-1}\right],
$$

Where:

v...Poisson's ratio [-].
Poisson's ratio has values close to 0.5 for incompressible elastomers and it is commonly considered to be 0.4995 for better convergence of calculations.

Tab. 1 and Tab. 2 show the calculated moduli for Shore A hardness of 80 and for Shore A hardness of 90, MR parameters as well as parameter of incompressibility. It is important to point out that $C_{01}$ parameter is 0.2 multiple of $C_{10}$ parameter.

Tab. 1 Shore A hardness of 80, Poisson's ratio $v=0.4995, C_{01}=0.2 \cdot C_{10}$

\begin{tabular}{|c|c|c|c|c|c|c|c|}
\hline Equation & $E[\mathrm{MPa}]$ & $G[\mathrm{MPa}]$ & $K[\mathrm{MPa}]$ & $C_{10}[\mathrm{MPa}]$ & $C_{01}[\mathrm{MPa}]$ & $\begin{array}{c}C_{10}-C_{01} \\
{[\mathrm{MPa}]}\end{array}$ & $d\left[\mathrm{MPa}^{-1}\right]$ \\
\hline 1 & 9.3513 & 3.1181 & 3117 & 1.5590 & 0.3118 & 1.2472 & 0.00064 \\
\hline 2 & 3.4545 & 1.1519 & 1151 & 0.5759 & 0.1151 & 0.4607 & 0.00173 \\
\hline 3 & 11.7525 & 3.9188 & 3917 & 1.9594 & 0.3918 & 1.5675 & 0.00051 \\
\hline 4 & 8.7252 & 2.9093 & 2909 & 1.4546 & 0.2909 & 1.1637 & 0.00068 \\
\hline
\end{tabular}

Tab. 1 Shore A hardness of 90, Poisson's ratio $v=0.4995, C_{01}=0.2 \cdot C_{10}$

\begin{tabular}{|c|c|c|c|c|c|c|c|}
\hline Equation & $E[\mathrm{MPa}]$ & $G[\mathrm{MPa}]$ & $K[\mathrm{MPa}]$ & $C_{10}[\mathrm{MPa}]$ & $C_{01}[\mathrm{MPa}]$ & $\begin{array}{c}C_{10}-C_{01} \\
{[\mathrm{MPa}]}\end{array}$ & $d\left[\mathrm{MPa}^{-1}\right]$ \\
\hline 1 & 20.8439 & 6.9503 & 6947 & 3.4751 & 0.6950 & 2.7801 & 0.00028 \\
\hline 2 & 4.3697 & 1.4570 & 1456 & 0.7285 & 0.1457 & 0.5828 & 0.00137 \\
\hline 3 & 17.9531 & 5.9863 & 5984 & 2.9931 & 0.5986 & 2.3945 & 0.00033 \\
\hline 4 & 13.5500 & 4.5181 & 4518 & 2.2590 & 0.4518 & 1.8072 & 0.00044 \\
\hline
\end{tabular}

Based on the values in Tabs. 1 and 2, it can be stated that there is also influence of hardness change because one equation can be suitable for hardness of 80 and any other can be suitable for hardness of 90 . The resulting MR parameters have to be verified because this is the only one possible way how to find out the most suitable equation for the given application. The mentioned fact is the reason for creation of FEM computational model of interaction between indenter and elastomeric material. The given model is used for simulation of hardness testing process by Shore A method.

\section{Verification of Mooney-Rivlin parameters}

Verification of MR parameters is on the basis of computational model of interaction between indenter of Shore A durometer and elastomer samples. The nodes or nodal points in number of 30551 as well as created simple computational model can be seen in the Fig. 5. The problem is modelled as planar stress (with type of element PLANE 182) because student's version of ANSYS Workbench is used. Therefore the thickness of the sample could not be considered in the calculation. The detailed image of mesh in contact area between indenter and tested elastomeric sample is reflected in Fig. 6.

The common construction steel is specified to be material for indenter, the elastic modulus is 200000
MPa and Poisson's ratio is 0.3 . The model of tested elastomeric sample is based on the two parameter MR model. The parameters, which can be found in Tabs. 1 and 2 , were used in relation to the computational modeling. Non-linear contact is used between indenter and tested elastomeric sample. In the Fig. 7, there is an example of the strain of tested elastomeric sample and it is based on definition of MR parameters, which were calculated by help of equation with designation as (1) and it was for hardness of 80 .

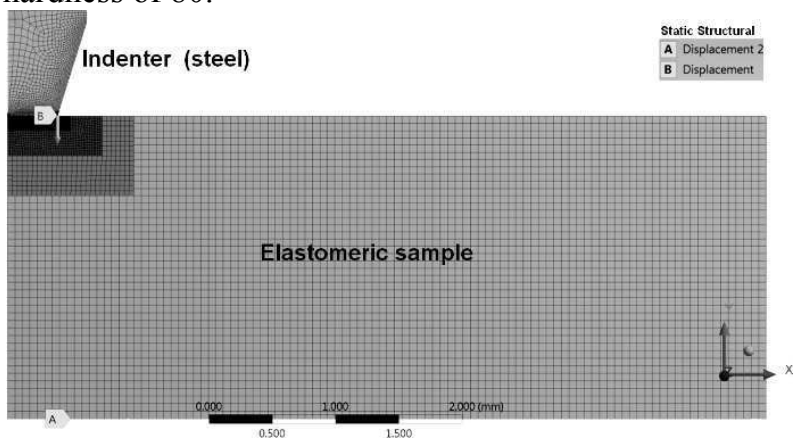

Fig. 5 Computational model for verification of calculated MR parameters [1]

Tab. 3 reflects the forces in the spring during experimental measurement as well as there are resulting reaction forces corresponding to indenter displacement by 0.5 and 
$0.25 \mathrm{~mm}$ in relation to the predetermined equations (equations with designation from 1 to 4 ). The preload or prestress of spring is $0.55 \mathrm{~N}$. In the case of calculated reaction forces, the given preload or prestress has to be also taken into account.

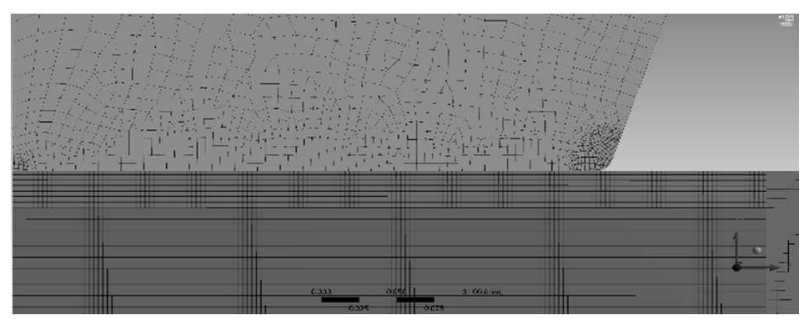

Fig. 6 Detailed image of contact area between indenter and tested elastomeric sample [1]

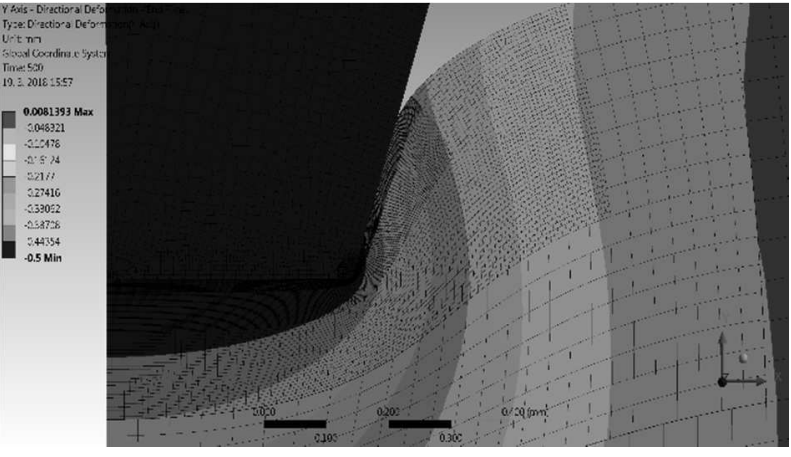

Fig. 7 Displacement filed of the tested sample after indenter displacement by $0.5 \mathrm{~mm}[1]$

Tab. 3 Calculated reaction forces with corresponding Shore A hardness

\begin{tabular}{|c|c|c|c|c|}
\hline \multicolumn{5}{|c|}{ Shore A hardness of 80 -indenter shift by $0.5 \mathrm{~mm}$} \\
\hline Equation & $\begin{array}{l}\text { Spring force with preload } \\
\text { (prestress) }[\mathrm{N}]\end{array}$ & $\begin{array}{l}\text { Resulting reaction force } \\
\qquad[\mathrm{N}]\end{array}$ & $\begin{array}{l}\text { Optimized reaction force } \\
\text { by preload (prestress) }[\mathrm{N}]\end{array}$ & $\begin{array}{c}\text { Hardness } \\
\text { [HSA] }\end{array}$ \\
\hline 1 & 6.55 & 5.77 & 6.32 & 77 \\
\hline 2 & 6.55 & - & - & - \\
\hline 3 & 6.55 & 7.25 & 7.80 & 97 \\
\hline 4 & 6.55 & - & - & - \\
\hline \multicolumn{5}{|c|}{ Shore A hardness of $90-$ indenter shift by $0.25 \mathrm{~mm}$} \\
\hline 1 & 7.3 & 6.31 & 6.86 & 84 \\
\hline 2 & 7.3 & 1.32 & 1.87 & 17 \\
\hline 3 & 7.3 & - & - & - \\
\hline 4 & 7.3 & 4.10 & 4.65 & 55 \\
\hline
\end{tabular}

- it was not determined because there was not convergence of calculation

Considering the results, it can be stated that more accurate results for hardness of 80 and 90 are obtained by help of equation, which is designated as 1 because after comparison of experimental results with the calculated results (using equation with designation as 1), the difference is $3.5 \%$ for hardness of 80 and $6 \%$ for hardness of 90. Based on the mentioned fact above, MR parameters for the range of hardness from 80 to 90 are recommended to be obtained from equation with designation as 1 .

\section{Computational model of "metal jerk block - barbell'6}

The mesh was created from four nodal (linear) shell elements - SHELL181. The critical conditions were defined for leg of construction, which is fastened with anchor bolts to the floor. The anchor bolt was replaced with the springs with stiffness of $245.19 \times 10^{6} \mathrm{~N} \cdot \mathrm{m}^{-1}$ to the because it roughly corresponds to stiffness of anchor bolt fastening or screw fastening [1]. Cowper-Symonds and Johnson-Cook models for elasto-plastic materials were also involved into computational modelling with parameters for steels $\mathrm{S} 355 \mathrm{~J} 2 \mathrm{H}$ and S355J2+N: $D=5000 \mathrm{~s}^{-1}$ and $q=2.5$ for Cowper-Symonds model [9] and $A=450 \mathrm{MPa}$, $B=782 \mathrm{MPa}, n=0.562$ (which representing the strain hardening effects of the material in quasistatic conditions) and $c=0.0247$ (which representing the strain rate sensitivity) for Johnson-Cook model [10]. Static analysis was performed for the given model in order to determine stress and strain for surface of drop or impact after the loading of construction with static force that corresponds to the weight of barbell. Based on the stress-strain analyses, it was possible to conclude that the designed construction was suitable and therefore, it was possible to create the computational model for dynamic analyses. The given model vas created on the basis of extension of the static model with model of dropping barbell. The resulting computational model can be seen in Fig. 8.

The calculation was made for $160 \mathrm{~kg}$ dropping or falling barbell (estimated maximum in-service loading) and for $220 \mathrm{~kg}$ dropping barbell (overloading). The construction steel with elastic modulus of $210000 \mathrm{MPa}$ and Poisson's ratio of 0.3 was selected for computational modeling of weightlifting axle. Computational modeling of elastomeric material was based on utilisation of hyperelastic two parameter MR model, the parameters of which were calculated by help of Shore A hardness of 88: $C_{10}=$ $2.2692[\mathrm{MPa}], C_{01}=0.56729[\mathrm{MPa}]$ and $d=0.00035267$ $\left[\mathrm{MPa}^{-1}\right]$.

For weight plates (weight loading) and weightlifting axle, the 8-node hexahedral elements are used. The predefined calculated initial velocity (speed) for weight plates (weight loading) and weightlifting axle was 5424.94 $\mathrm{mm} \cdot \mathrm{s}^{-1}$ and it corresponds to velocity or speed during the free fall (drop) after the overcoming of $1500 \mathrm{~mm}$ distance. The calculation of the impact of barbell (weight of weight plates along with weightlifting axle) onto construction was solved with Autodyn explicit integration scheme. 


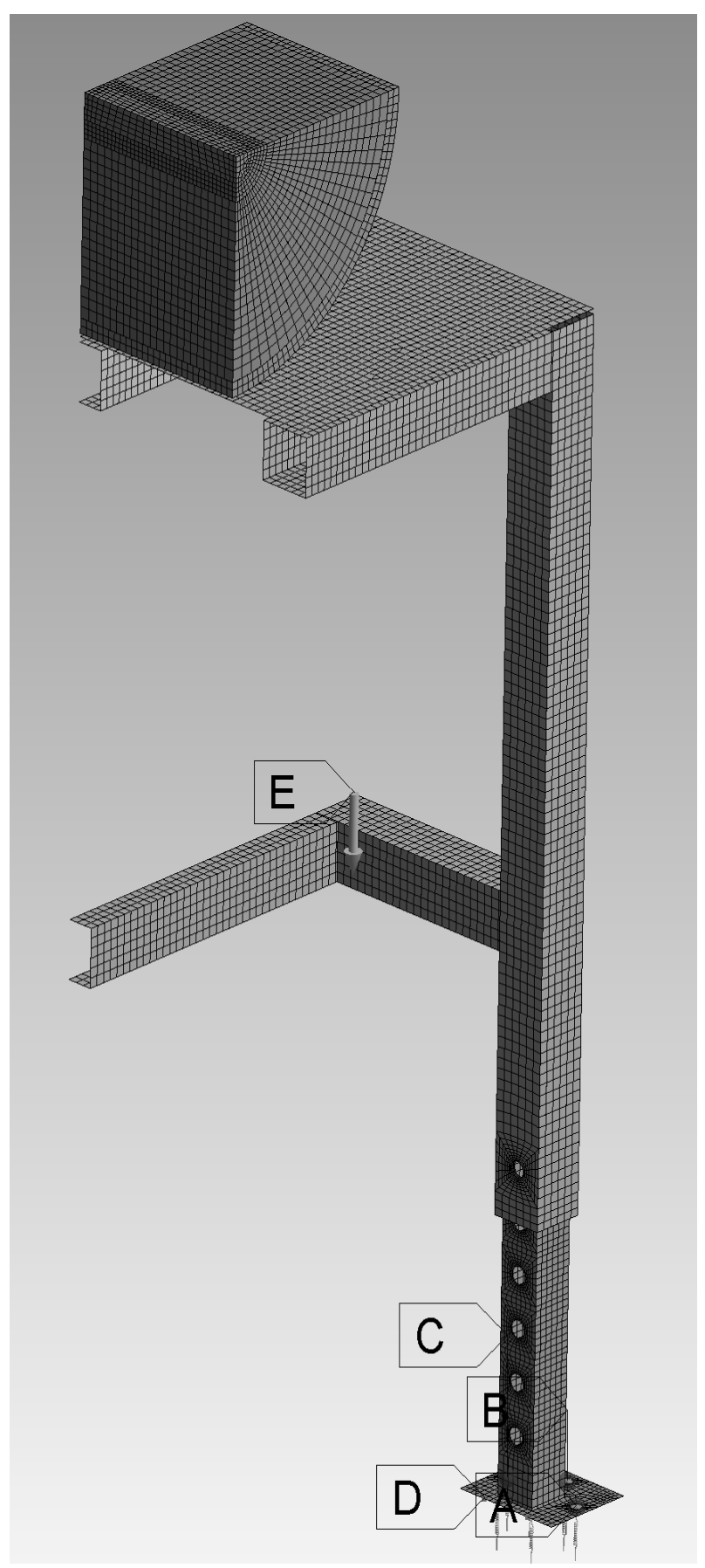

Fig. 8 Computational model of "construction - barbell" system for dynamic analysis [1]

Evaluation of stresses and strain was performed for the area under the impact loading. The maximum vonMises stress is $485.7 \mathrm{MPa}$. The stress-strain analyses of the metal construction led to findings that after impact loading, the yield point exceeded the limit in relation to the given material and the given fact was also confirmed due to high strain, which is $6.9 \mathrm{~mm}$. Based on the dynamic analysis results, it can be stated that the design of the construction is not suitable and therefore the construction in the area under impact loading was strengthened with bracing as it can be seen in Fig. 9. The additional bracing was included into the computational model to be and it can be seen in the Fig. 10 .

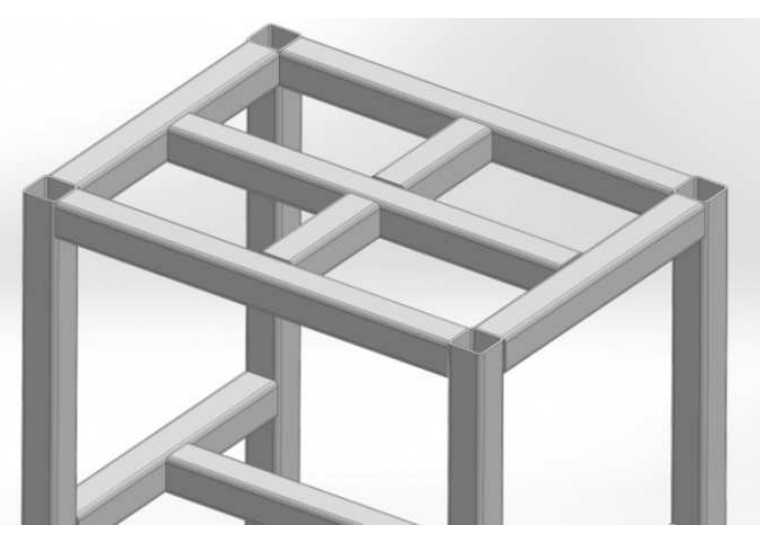

Fig. 9 Strengthening of the construction with bracing [1]

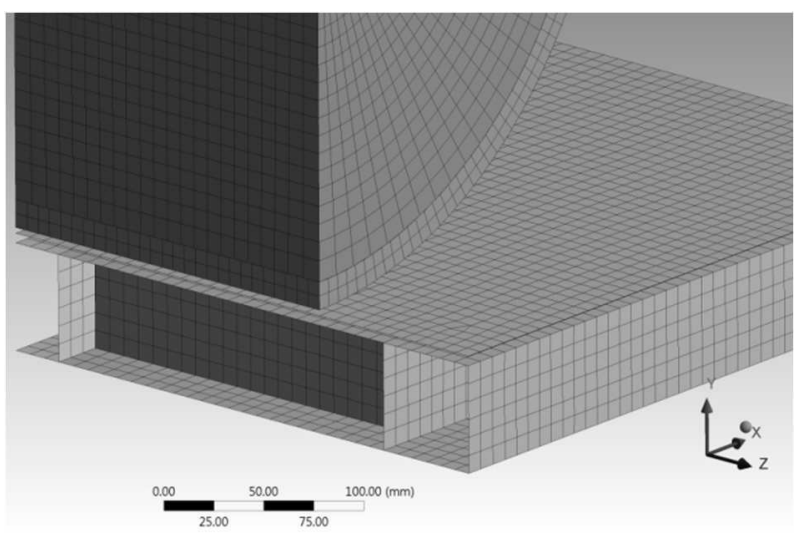

Fig. 10 Optimised computational model for the area of construction under the impact loading [1]

The maximum von-Mises stress for $160 \mathrm{~kg}$ barbell is 421.3 MPa (see Fig. 11).

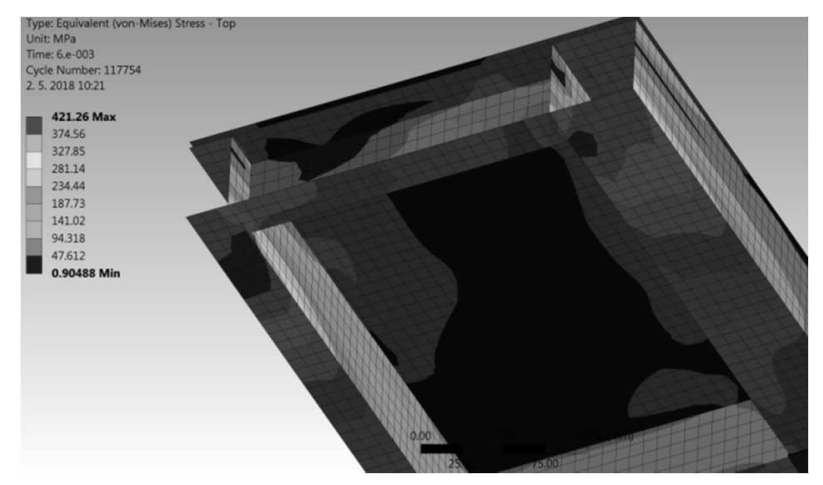

Fig. 11 Image of von-Mises stresses [MPa] for the area of construction under the impact loading

\section{Conclusion}

Based on the obtained results, it can be concluded that we recommend to use Gent equation (with designation as 1) [2] for calculation of MR parameters for hardenss of 80 and 90.

The evaluation of the stress-strain states for the designed construction was based on the computational model in explicit dynamics with utilisation of Mooney-Rivlin model for elastomeric material and constitutive models for elasto-plastic materials while the effect of strain velocity (speed) was also taken into account. 
From the aspect of stress-strain analysis results, it can be concluded that after optimisation of the construction for training purposes, the yield point of materials was not beyond the limit for any area under the impact loading during in-service loading conditions. The maximum calculated von-Mises stress for the S355J2H steel profiles is lower about by $10.4 \%$ in comparison with yield point for the mentioned material and it is $470 \mathrm{MPa}$.

\section{Acknowledgement}

This research work had been supported by the Cultural and Educational Grant Agency of the Slovak Republic (KEGA), project No. KEGA 002TnUAD-4/2019.

\section{References}

[1] KVASNICA, T. (2018). Examination of Designed Structure Used for Weightlifting in CrossFit by FEM (In Slovak), Diploma thesis, Faculty of Industrial Technologies, Alexander Dubcek University of Trencin Puchov.

[2] Hyperelastic Coefficient Convertion, (2011). Available at: https://polymerfem.com/ forum/polymerfem-downloads/general-hyperelastic-models/1237-linear-elastic-hyperelastic-coefficientconversion

[3] REUSS, B., (2011). Convert Durometer to Young's Modulus. Available at: https://www.cati.com/blog/ 2011/07/convert-durometer-to-youngs-modulus/

[4] Mooney Rivlin Constants, (2005). Available at: http://xansys.org/forum/viewtopic.php? $\mathrm{p}=51617 \&$ sid $=$ 609a8612c34eb2eec373756fd062aea2

[5] Constitutive Models for Rubber, (1999). DORFMANN, A., MUHR, A. (ed.). Rotterdam: A.A.Balkema. ISBN 90-5809-113-9.

[6] KLIMENDA, F., RYCHLÍKOVÁ, L., HUSÁR, Š., SOUKUP, J. (2017). Dissemination of Waves in Thin Plates, Manufacturing Technology, Vol. 17, no. 6, 2017, pp. 863 - 869, ISSN: 1213-2489
[7] GORBUNOV, M., GERLICI, J., KARA, S., NOZHENKO, O., CHEMYAK, G., KRAVCHENKO, K., LACK, T.: New principle schemes of freight car bodies, Manufacturing Technology, Vol. 18, issue 2, 2018, pages 233238, ISSN 1213-2489

[8] GERLICI, J., GORBUNOV, M., KRAVCHENKO, K., PROSVIROVA, O, LACK, T., HAUSER, V. (2018). Assessment of innovative methods of the rolling stock brake system efficiency increasing, Manufacturing Technology, Vol. 18, issue 2, 2018, pages 35-38, ISSN 1213-2489

[9] AVALLE, M., BELINGARDI, G., GAMARINO, M. (2004). An inverse method for the identification of strain-rate sensitivity parameters of sheet steels. In: Structures Under Shock and Impact VIII. Southampton. ISBN 1-85312-706-X. Available at: https://www.witpress.com/Secure/elibrary/papers/SU04/SU04002FU.pdf

[10] FORNI, D., CHIAIA, B., CADONI, E. (2016). Mechanical Properties of S355 Under Extreme Coupled Effect of High Temperatures and High Strain Rates. In: ECCOMAS Congress 2016 VII European Congress on Computational Methods in Applied Sciences and Engineering [online]. Available at: www.eccomas2016.org/proceedings/pdf/5566.pdf

[11] SOUKUP, J., ŽMINDÁK, M., SKOČILAS, J., RYCHLÍKOVÁ, L. (2014). Application of meshfree methods in transient dynamic analysis of orthotropic plates, Manufacturing Technology, Vol. 14 , issue 3, 2014, pages 441-447, ISSN 1213-2489

[12] DIŽO, J., STEIŠUNAS, S., BLATNICKÝ, M. (2016). Simulation analysis of the effects of a rail vehicle running with wheel flat; Manufacturing Technology, Vol. 16, issue 5, 2016, pages 889896, ISSN 1213-2489 